\title{
Erratum to: Equilibration kinetics in isolated and membrane- bound photosynthetic reaction centers upon illumination: a method to determine the photoexcitation rate
}

\author{
Anthony J. Manzo • Alexander O. Goushcha \\ Yuri M. Barabash • Valery N. Kharkyanen • \\ Gary W. Scott
}

Published online: 30 October 2009

(C) Springer Science+Business Media B.V. 2009

Erratum to: Photosynth Res (2009) 101:35-45

DOI 10.1007/s11120-009-9461-z

The bottom graph of Fig. 3 in the original publication was mistakenly repeated as Fig. 4 . The correct Fig. 4 is shown below.
The online version of the original article can be found under doi:10.1007/s11120-009-9461-z.

A. J. Manzo · A. O. Goushcha · G. W. Scott ( $)$

Department of Chemistry, UC Riverside, Riverside, CA 92521,

USA

e-mail: gary.scott@ucr.edu

A. O. Goushcha · Y. M. Barabash · V. N. Kharkyanen Institute of Physics, Nat. Acad. Sci. Ukraine, Kyiv, Ukraine

\section{A. J. Manzo}

Department of Chemistry, University of Michigan, Ann Arbor, MI 48109, USA

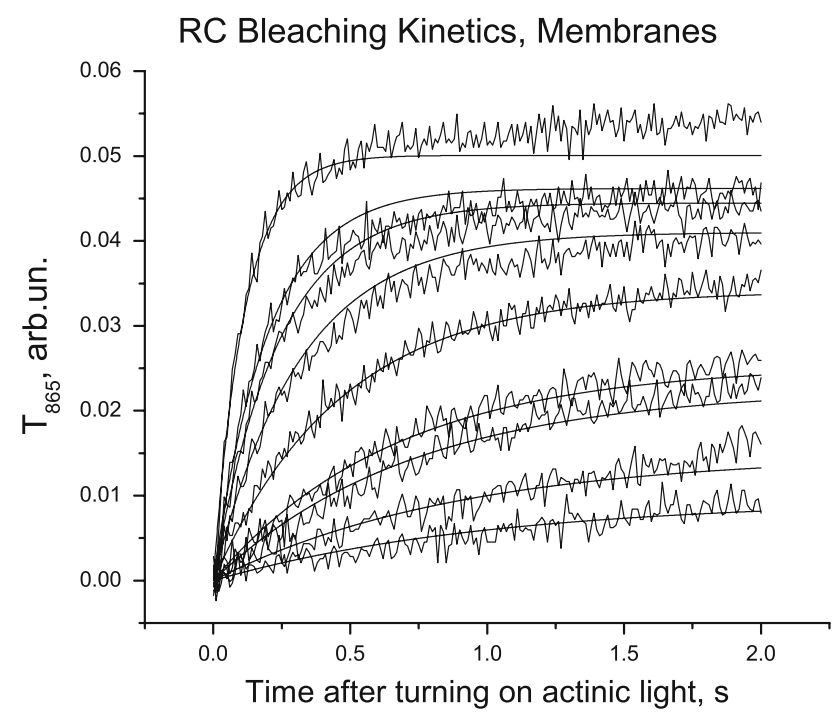

Fig. 4 Bleaching kinetics of membrane bound RCs after turning on $\mathrm{CW}$ illumination for a 2 -second time interval. The transmittance at a wavelength of $865 \mathrm{~nm}, \mathbf{T}_{865}$, versus time is shown. The smooth line shows the results of fitting using Method 2 